\title{
Sacral osteoid osteoma: a rare cause of inflammatory back pain and sacroiliitis in a young man
}

\author{
Kunal Chandwar 지, ${ }^{1}$ Harsh Lathiya, ${ }^{2}$ Abhishek Gohel, ${ }^{3}$ Chandani Shah ${ }^{4}$
}

${ }^{1}$ Department of Clinical Immunology and Rheumatology, King George's Medical University, Lucknow, Uttar Pradesh, India ${ }^{2}$ Department of Radiology, Zydus Research Center, Ahmedabad, Gujarat, India ${ }^{3}$ Department of Neurology, NIMHANS, Bangalore, Karnataka, India ${ }^{4}$ Department of Neurology, Sawai Man Singh Medical College and Hospital, Jaipur, Rajasthan, India

\section{Correspondence to} Dr Kunal Chandwar; kunalchandwar@gmail.com

Accepted 28 July 2021

\section{DESCRIPTION}

A 29-year-old man with a 10 -year history of low back pain presented with increasing frequency and intensity of inflammatory back pain for the last 1 month with early morning stiffness of about $30 \mathrm{~min}$, pain maximum at night, often disturbing sleep and excellent response to NSAID (Non Steroidal Anti-Inflammatory drugs). On examination, the Patrick's/flexion, abduction and external rotation test and pelvic compression test were suggestive of right sacroiliac involvement, but there was no spinal movement restriction and chest expansion was normal. The inflammatory markers and blood counts were within limits and an HLAB27 was negative. The patient, a neurology fellow, was advised a radiograph of sacroiliac joints but preferred an MRI over it. MRI performed showed low signal intensity nidus with surrounding bone marrow oedema in the anterior juxta-articular region of the right sacral ala. The articular margins were normal without any erosive changes that ruled out acute or chronic arthritis (figure 1). Further, CT was done that revealed radiolucent nidus

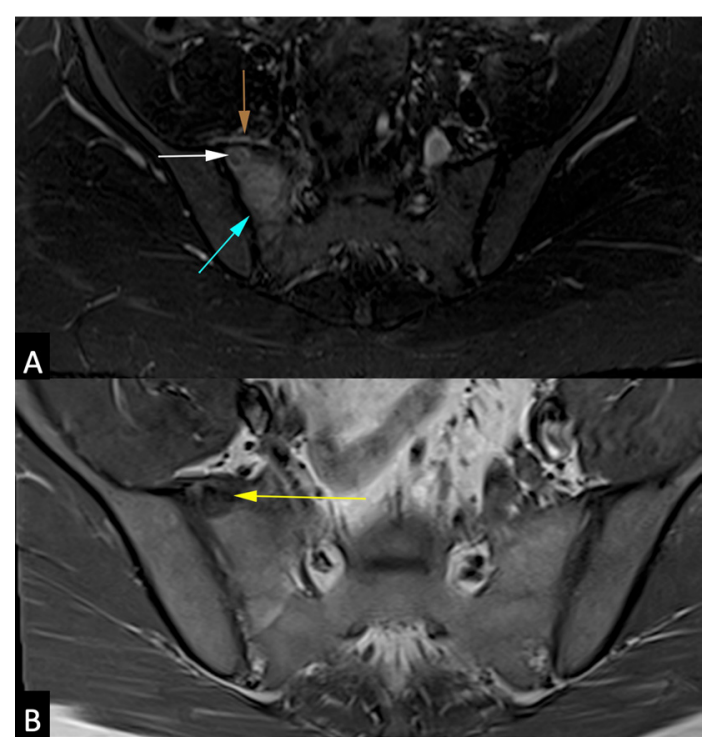

Figure 1 (A) Axial STIR (Short Tau Inversion Recovery) image demonstrates rounded low signal intensity nidus (white arrow) surrounded by hyperintense signal intensity bone marrow oedema (cyan arrow) involving anterior portion of right sacral ala. Thin strip of fluid signal intensity is also seen anterior to right sacral ala (orange arrow). (B) Axial T1 image nicely demonstrates the rounded low signal intensity nidus (yellow arrow) at the anterior portion of right sacral ala. The articular margin at right sacroiliac joint appears normal.

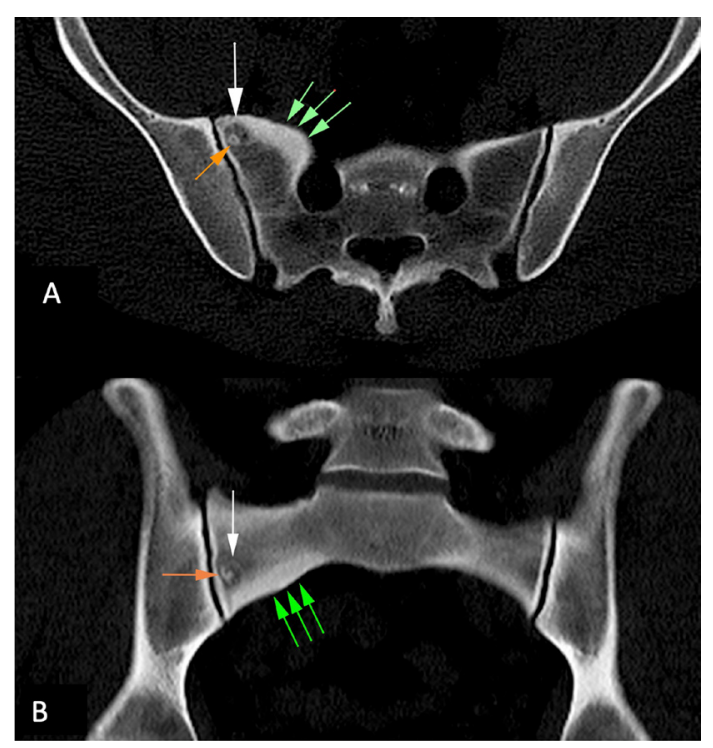

Figure 2 Axial (A) and coronal (B) CT images in bone window demonstrates the radiolucent nidus (white arrow) with central calcification (orange arrow) with surrounding reactive sclerosis (green arrows) in anterior portion of right sacral ala. The articular margins are smooth without any irregularity or erosions.

with central calcification and surrounding reactive sclerosis in the anterior aspect of right sacral ala (figure 2), which confirmed the lesion to be an osteoid osteoma.

Osteoid osteoma is a solitary benign tumour of the bone that classically affects men (M:F 2-3:1) in their second decade. ${ }^{1}$ The pain that usually peaks at night in this condition is attributed to the prostaglandins that are released by the tumour. ${ }^{2}$ Though characteristics of pain, response to NSAIDs and radiological features make the diagnosis certain ${ }^{1}$ involvement of pelvic bones is uncommon in the condition that predominantly involves bones of

\section{Patient's perspective}

The pain was very vague, dull aching and I did not feel any weakness as such. Occasionally, other people would notice that my style of walking has changed a bit. Since there was no weakness, I was adviced against imaging. However, the pain increased over last few months and hindered my sleep. That is when I opted for an MRI and subsequently got the diagnosis confirmed by a CT. Since it is a benign lesion, thankfully, I can rest assured! 


\section{Learning points}

- Not all young men presenting with inflammatory back pain have spondyloarthropathy.

- When suspecting an osteoid osteoma getting a CT would be the investigation of choice.

- The presence of bone marrow oedema may clinch the diagnosis of spondylarthritis in suspected individuals but it is worthwhile to remember that it can be seen in other conditions also including infections and tumours such as this case.

lower limb, juxta-articular location further complicates the diagnosis as multiple structures can be the source of the pain and confuses the clinician to clinch the correct diagnosis. The classic radiographic abnormality of a radiolucent nidus with sclerotic margins is present in less than half of the patients with the condition and exuberant osseous and soft tissue oedema may obscure the nidus in MRI making CT the investigation of choice to diagnose the condition. ${ }^{3}$ Treatment options include radiofrequency ablation, surgical resection (preferably CT-guided) or MR-guided high-frequency ultrasound ${ }^{4}$ in patients with functional impairment (severe pain, limp) not controlled with NSAIDs.

Our patient was older, had a juxta-articular sacral osteoid osteoma with a history suggestive of inflammatory back pain and examination suggestive of right sacroiliac joint involvement. Being a young man, he could have been mislabelled as having spondyloarthropathy had imaging not been performed.
Prostaglandins secreted from the osteoma probably resulted in the extensive bone marrow oedema of the right sacral area, associated pain and excellent response to NSAID. The pain was controlled with NSAIDs, and the patient opted for conservative management over intervention.

Twitter Kunal Chandwar @kunalchandwar

Contributors KC was involved with patient's diagnosis and treatment and primary write-up of the article. HL was the radiologist who suggested the diagnosis and reported the $\mathrm{CT}$ and MRI, HL was also closely involved with the image selection and write-up. AG and CS were involved in patient care and diagnosis and editing and proof reading the draft.

Funding The authors have not declared a specific grant for this research from any funding agency in the public, commercial or not-for-profit sectors.

Competing interests None declared.

Patient consent for publication Obtained.

Provenance and peer review Not commissioned; externally peer reviewed.

ORCID iD

Kunal Chandwar http://orcid.org/0000-0002-0499-0641

\section{REFERENCES}

1 Orlowski JP, Mercer RD. Osteoid osteoma in children and young adults. Pediatrics 1977;59:526-32.

2 Arkader A, Gebhardt MC, Dormans JP. Bone and soft-tissue tumors. In: Weinstein SL, Flynn JM, eds. Lovell and Winter's Pediatric Orthopaedics. 7th ed. Philadelphia: Wolters Kluwer Health, 2014: 1-426.

3 Iyer RS, Chapman T, Chew FS. Pediatric bone imaging: diagnostic imaging of osteoid osteoma. AJR Am J Roentgenol 2012;198:1039-52.

4 Sharma KV, Yarmolenko PS, Celik H, et al. Comparison of noninvasive high-intensity focused ultrasound with radiofrequency ablation of osteoid osteoma. J Pediatr 2017;190:222-8.

Copyright 2021 BMJ Publishing Group. All rights reserved. For permission to reuse any of this content visit https://www.bmj.com/company/products-services/rights-and-licensing/permissions/

BMJ Case Report Fellows may re-use this article for personal use and teaching without any further permission.

Become a Fellow of BMJ Case Reports today and you can:

- Submit as many cases as you like

- Enjoy fast sympathetic peer review and rapid publication of accepted articles

- Access all the published articles

- Re-use any of the published material for personal use and teaching without further permission

Customer Service

If you have any further queries about your subscription, please contact our customer services team on +44 (0) 2071111105 or via email at support@bmj.com.

Visit casereports.bmj.com for more articles like this and to become a Fellow 